\title{
Snowdrift modelling in a wind tunnel: vertical and horizontal variation of the snow flux
}

\author{
Florence NaAim-Bouvet, Mohamed Naaim \\ Division Nivologie, CEMAGREF, Domaine Universitaire, BP 76, 38402 Saint-Martin-d'Hères, France
}

\begin{abstract}
This paper deals with the influence of the vertical and horizontal variation of aeolian snow flux on estimations of snow-storm duration and on snowdrift patterns simulated in a wind tunnel.

First of all, we shall review recent developments, including our own simulations, concerning the horizontal increase of mass flux until drifting-snow saturation has been reached.

Next, after a critical examination of various snowdrift-modelling criteria, we present the results of an experiment undertaken in our wind tunnel: We studied cross-section drift-area changes behind a small-scale snow fence as a function of time for different fetches but for the same mean wind speed at the beginning of the testing section. For each fetch, we carried out vertical profiles of sand particles using image processing and we studied the geometrical parameters of the drift. We conclude that changes in the crosssection drift area depend on the ablation length and if particle saturation is not reached, the use of a storm-duration scale leads to overevaluation of prototype storm duration. Moreover, we point out that drift pattern vary as a function of the concentration profiles.
\end{abstract}

\section{NOTATION}

$A$

$C_{\mathrm{D}}$

$D_{\mathrm{p}}$

$g$

$H$

$L$

$p$

$t$

t

$U_{0}$

$U_{\mathrm{F}}$

$u_{*}$

$u_{* \text { th }}$

$x$

$y$

$\gamma$

$\lambda$

$\bar{\nu}_{\mathrm{i}}$

$\rho$

$\sigma$

$\tau_{i j}^{\mathrm{t}}$

\author{
Planform drift area $\left(\mathrm{m}^{2}\right)$ \\ Drag coefficient \\ Particle diameter $(\mathrm{m})$ \\ Gravitational acceleration $\left(\mathrm{m} \mathrm{s}^{-2}\right)$ \\ Reference height (m) \\ Reference length (m) \\ Pressure $\left(\mathrm{N} \mathrm{m}^{-2}\right)$ \\ Time (s) \\ Reference speed $\left(\mathrm{ms}^{-1}\right)$ \\ Threshold speed at a reference height $\left(\mathrm{m} \mathrm{s}^{-2}\right)$ \\ Particle-settling velocity $\left(\mathrm{m} \mathrm{s}^{-2}\right)$ \\ Shear velocity $\left(\mathrm{m} \mathrm{s}^{-2}\right)$ \\ Threshold shear velocity $\left(\mathrm{m} \mathrm{s}^{-2}\right)$ \\ Horizontal component $(\mathrm{m})$ \\ Vertical component $(\mathrm{m})$ \\ Bulk density of deposited snow $\left(\mathrm{kg} \mathrm{m}^{-3}\right)$ \\ Length of ablation zone $(\mathrm{m})$ \\ Mean velocity component in $O x_{\mathrm{i}}$ direction $\left(\mathrm{m} \mathrm{s}^{-1}\right)$ \\ Air density $\left(\mathrm{kg} \mathrm{m}^{-3}\right)$ \\ Particle density $\left(\mathrm{kg} \mathrm{m}^{-3}\right)$ \\ Components of the turbulent stress sensor $\left(\mathrm{N} \mathrm{m}^{-2}\right)$ \\ Components of the laminar stress sensor $\left(\mathrm{N} \mathrm{m}^{-2}\right)$
}

\section{INTRODUCTION}

In high mountain areas, blowing snow produces cornices creating dangerous avalanche starting zones. In other areas, blowing snow reduces visibility and creates snowdrifts. Drifting snow poses economic problems, especially for roads and railways. It is therefore necessary to take snowdrift formation into account both for predicting drift patterns and for controlling them. However, it is timehttps://doi.org/10.3189/1998AoG26-1-212-216 Published online by Cambridge University Press consuming and often unrealistic to study full-scale snowdrifting in the field. Scientists have performed modelling in wind-tunnels since the 1930s. In practice, similitude requirements cannot all be satisfied simultaneously and many articles have been published on this subject (Iversen, 1980, 1984; Tabler, 1980; Anno, 1984; Kind, 1986; ...). None of the authors has dealt with the influence of the vertical and horizontal variation of the snowdrift flux on storm-duration estimation and on the pattern of drifts. This is the main purpose of this paper.

\section{VERTICAL AND HORIZONTAL VARIATION OF PARTICLE FLUX IN AEOLIAN GRAIN TRANSPORT}

There are many published empirical formulae for determining the mass flux of drifting snow. In most experiments on drifting snow, estimates of storm duration are based on these formulae. However, very few papers have dealt with the horizontal increase (in the direction of the wind) of the mass flux up to the saturation point of drifting snow (or sand). Therefore, we shall review recent developments on this specific point.

According to Anderson and Haff (1991), initial entrainment of sand particles is entirely aerodynamic. Limiting the discussion to saltation, all grains that are ejected from the bed return to the bed owing to gravitational acceleration. It is the subsequent impacts of saltating grains that are responsible for most of the ejection of grains. Grainbed interaction can be formulated statistically by the "splash function" that returns the number of ejected particles, the probability distribution of their ejection velocities and the velocities of the rebounding grain for a given distribution of impact velocities: the saltating population may be represented ideally as consisting of particles having a long 
trajectory with high impact energy and the reptating population may be idealized as consisting of particles having a short trajectory with low impact energy. A numerical model of saltation based on the splash function generated from both physical and numerical simulations has been constructed by Anderson and Haff (1991). It allows simulation from ejection by aerodynamic entrainment to steady state. For sand $\left(D_{\mathrm{p}}=0.25 \mathrm{~mm}\right.$ and $\left.u_{*}=0.6 \mathrm{~m} \mathrm{~s}^{-1}\right)$, their results show that a steady-state mass flux is reached after $1-2$ seconds; this corresponds to an erosion area stretching for about $10 \mathrm{~m}$.

Based on experimental data, Kobayashi (1972) showed that the fetch necessary to obtain saturation ranged from 30 to $60 \mathrm{~m}$. Takeuchi (1980) estimated that the snowdrift flux reaches saturation about $350 \mathrm{~m}$ downwind from the starting point. In this case, vertical profiles of drift flux were measured from the snow surface to a height of $30 \mathrm{~cm}$. These measurements include particles in suspension. Therefore we can make the assumption that the difference between these two results is due to the influence of the turbulent-diffusion mechanism which increases the length of the fetch necessary for obtaining saturation. In order to isolate the influence of suspension, we constructed a simple numerical model based on continuum theory, including saltation and suspension, to simulate the development of drifting snow in a boundary layer. The saltation layer is described by means of the splash function defined for sand. This numerical model (NaaimBouvet and others, 1996) shows that the length necessary for obtaining fully developed drifting snow is a few metres (we consider only the first $30 \mathrm{~cm}$ layer above ground level). In these calculations, the numerical grid is fine in order to reduce numerical diffusion $(\mathrm{d} x=10 \mathrm{~cm}$ and $\mathrm{d} y=1 \mathrm{~cm})$. These numerical results are confirmed by experimental results carried out in our wind tunnel (Fig. 3): we estimate that the sand-drift flux reaches saturation a few metres downwind from the starting point. Thus it would appear that the difference between Anderson and Haff's and Takeuchi's results is not due to the influence of the suspension layer. It must be acknowledged that wind gusts are not taken into account in numerical simulations and in wind-tunnel experiments. In conclusion, the development length is dependent on the splash function and the splash function defined for sand differs from the splash function of snow, which can depend on cohesion or temperature.

On that subject, the study of ripple formation can provide some interesting information. Anderson (1987) showed that reptating grains lead to ripple formation: the wavelength is scaled by the mean reptation length. It would be reasonable to assume that the absence of ripple formation means that reptating grains are scarce. Consequently, the splash function defined for sand, which includes reptating grains, is modified. Concerning drifting snow, ripples only form in cold loose snow (Mellor, 1965). Precisely, for loose granular snow particles, the fetch necessary to reach saturation seems to be several tens of centimetres according to wind-tunnel experiments carried out by Kosugi and others (1992).

For a given flow, the vertical profile of the mass flux depends on the ablation-zone length. But, in the various papers dealing with snowdrift modelling, scientists do not make allowance for this phenomenon: they assume that the particle-mass flux reaches saturation instantaneously. Therefore, it seems important to study the influence of mass-flux vertical profiles on similitude criteria.

\section{SIMILITUDE REQUIREMENTS FOR MODELLING} A SNOWDRIFT

Physical modelling allows the study of snow storms in small-scale laboratory models. However, the validity of full-scale prediction (drift patterns and storm duration) from small-scale experiments by using similarity criteria poses a problem: the large number of modelling parameters cannot be satisfied. A lot of experiments have been carried out by many scientists. But difficulties lie in the disagreement between authors concerning the most important and appropriate sets of modelling requirements. By way of introduction, the different points of view are examined.

If the following requirements are imposed: geometrical dimensions are reduced by the same part, turbulent model flow occurs and the angle of repose between model and prototype is the same, then important divergences concerning the appropriate wind speed and storm duration appear within the scientific community.

\section{Wind-speed criteria}

Whereas some authors (Iversen, 1980, 1984; Tabler, 1980; Kind, 1986) have recommended the use of the Froude number $U^{2} / H g$, the densimetric Froude number $\left(\rho U^{2} /(\sigma g H)\right.$ or the modified densimetric Froude number $\left(\rho U^{2}\left(1-U_{0} / U\right)\right)$ / $(\sigma g H)$, Anno (1984) proposed using $u_{*} / u_{* \text { th }}$. The Froude number derives from the particle-trajectory equation of motion. In this case, it is closely linked to $\left.\left(C_{\mathrm{D}} \rho H\right) / \sigma D_{\mathrm{p}}\right)$ : if both parameters are satisfied, it is not possible to reduce significantly the scale of the prototype using air as the model fluid. According to our wind-tunnel results (Naaim-Bouvet, 1995), the Froude number by itself is not a relevant parameter and the wind-speed ratio $u_{*} / u_{* \text { th }}$ is more appropriate. Moreover, if the two requirements $U^{2} / \mathrm{Hg}$ and $\left.\left(C_{\mathrm{D}} \rho H\right) / \sigma D_{\mathrm{p}}\right)$ are satisfied, the wind-speed ratio $u_{*} / u_{* \text { th }}$ is automatically matched between model and prototype (Naaim-Bouvet, 1997).

\section{Storm-duration criterion}

The commonest parameter is $\left(\rho U^{2} /(\sigma g H)\right.$ or $(\rho U t /(\gamma H)$ (Tabler, 1980; Kind, 1986). But particles or wind speeds differ from erosion or deposition speeds. In fact, $\left(\rho U^{2} /(\sigma g H)\right.$ has physical foundations only if the forgoing requirements are satisfied simultaneously (Naaim-Bouvet, 1997): $U^{2} / \mathrm{Hg}$, $\left.\left(C_{\mathrm{D}} \rho H\right) / \sigma D_{\mathrm{p}}\right)$ (derived from the particle-trajectory equation of motion) and the dimensionless drift rate $\rho / \sigma\left[1-H_{0} / U\right]$ $\left[U^{2} /(g H][(U t) / H]\right.$ (derived from the mass rate of motion of saltating particles). As we have said previously, reduction of scale is small in this case. The dimensionless drift rate was introduced by Iversen (1980). This approach appeared to be truly innovative. After an initial proposal $\left[\left(u_{*} t\right) / L\right]\left[\left(\rho u_{*}^{2}\right) /(\sigma g H)\right]$ $\left[1-u_{* \text { th }} / u_{*}\right]$, he suggested a more general form in which he used an analytic expression of $\Im$ according to wind-tunnel simulations:

$$
\begin{aligned}
\frac{A}{L^{2}}= & \left(\frac{u_{*} t}{L}\right) \frac{\rho u_{*}^{2}}{\sigma g H}\left(\frac{1-u_{* \mathrm{th}}}{u_{*}}\right) \Im \\
& \left(\frac{u(H) L}{\nu}, \frac{h}{H}, \frac{l}{L}, \frac{z_{0}}{H}, \frac{z_{0} \prime}{H}, \frac{\rho}{\sigma}, \frac{U_{\mathrm{F}}}{u_{* \mathrm{th}}}, \frac{u_{*}^{2}}{g H}\right) .
\end{aligned}
$$

But none of the above-mentioned scientists have dealt with the influence of the particle-concentration profile. 


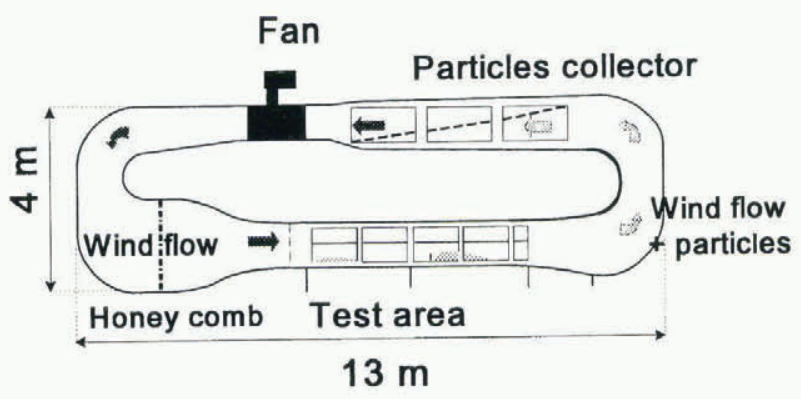

Fig. 1. Wind tunnel.

\section{INFLUENGE OF PARTICLE-CONGENTRATION PROFILE ON SIMILITUDE REQUIREMENTS}

\subsection{Experimental device description}

The experimental system was specially designed for dynamic studies of aeolian transport. The experimental set-up is shown in Figures 1 and 2. The $13 \mathrm{~m}$ long wind tunnel has a $5 \mathrm{~m}$ test area of uniform cross-section $100 \times 50 \mathrm{~cm}$ and is protected by a filter in order to hold back the particles. The height of the boundary layer is approximately $20 \mathrm{~cm}$. The wind tunnel is equipped with a hot-film anemometer (oneand two-dimensional), installed on a support with three-dimensional displacement. A laser diode measures the height of the deposit. Particle concentration is determined by image processing (Naaim and Martinez, 1995). The data-acquisition system consists of two modules: an optical device and a data logger. The optical device allows observation of the particles using a laser plane. The laser emits an incident beam that passes through a beam spreader and reflects off a mirror. The resulting laser plane is about $4 \mathrm{~mm}$ thick. This illuminates the particles, whose position is recorded by a camera and VCR. The analog-recorded image is digitized by a Matrox card. The main advantages of this system are that it is non-invasive and simultaneously measures particle velocities and position throughout the flow.

\subsection{Influence of particle-concentration profiles on the speed of drift formation}

The similitude requirement which is especially modified by concentration profiles is the storm-duration criterion. Therefore, we used the wind tunnel and image processing to study sand-mass concentration vertical profiles for several ablation-zone lengths and for the same friction velocity (Fig. 3).

For the same experimental conditions (particles and reference speed windward of the erosion zone), we studied snowdrift de-

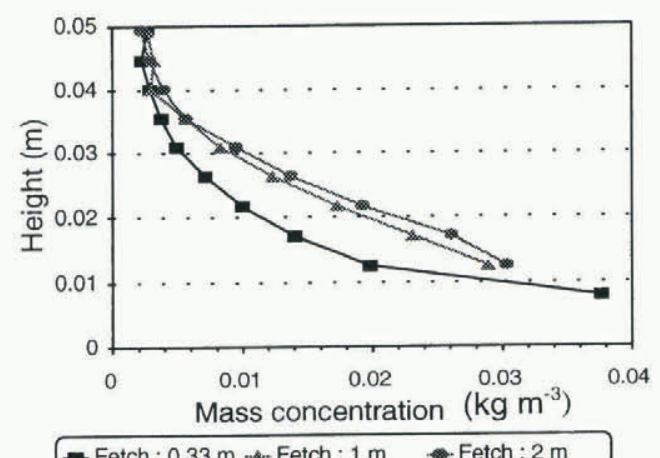

Fig. 3. Sand-mass concentration as a function of height for various ablation-zone lengths (fetches).

velopment behind a snow fence, $4 \mathrm{~cm}$ high without porosity and with a bottom gap $0.8 \mathrm{~cm}$ high, placed in the testing section of the wind tunnel downstream from the ablation zone.

It can be seen from the experimental results that as the fetch increases so does the particle concentration (Fig. 3). The consequence of this is an increase in the speed of drift formation (Fig. 4).

In the experiments performed by Iversen (1982), the fetch was $1.4 \mathrm{~m}$ and it is quite justifiable to wonder whether particle saturation was reached for this length. If this is not the case, it is necessary to introduce into the function $\Im$ a new variable $\lambda$ corresponding to the length of the ablation zone and on which the mass flux depends.

If the particle concentration is not saturated, use of the function $\Im$ without modification leads to an overestimation of the duration of drift growth. Moreover, in a paper published in 1984, Iversen compared the small-scale outdoor experiments from Tabler with his own wind-tunnel simulation for the same snow fence $(50 \%$ porous fence with a bottom gap of $0.1 H$ ). In both cases, he looked for an analytic expression for the modelling prediction in Equation (2). He obtained the following relationship in the wind tunnel:

$$
\frac{A}{L^{2}}=B\left(\frac{U t}{L}\right)\left(\frac{\rho U^{2}}{\sigma g H}\right)\left(1-\exp \left(-6.2\left(U / U_{\mathrm{t}}-1\right)\right)\right)
$$

where $U\left(\mathrm{~m} \mathrm{~s}^{-1}\right)$ is the undisturbed wind speed at the top of the fence, $U_{\mathrm{t}}\left(\mathrm{m} \mathrm{s}^{-1}\right)$ is the value of $U$ at threshold and $B$ is a constant equal to $4.98 \times 10^{-4}$. But for small-scale outdoor simulations, the value of $B$ is $9.89 \times 10^{-4}$. Iversen did not explain this difference (drift growth is twice as fast in the case of outdoor full-scale modelling). That can simply be due to unsaturated particle-concentration profiles in the wind tunnel.

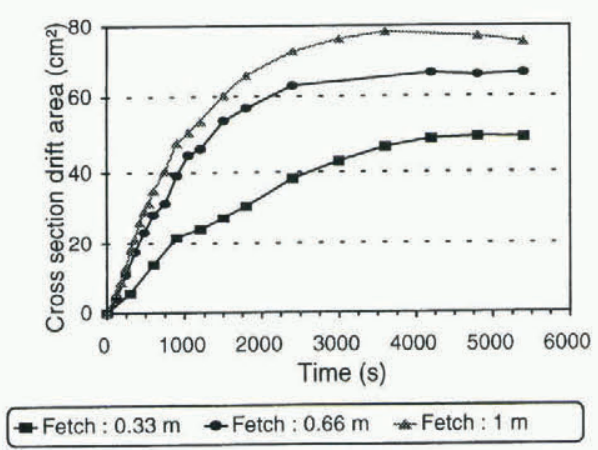

Fig. 4. Cross-section of drift area as a function of time for various ablation-zone lengths. 


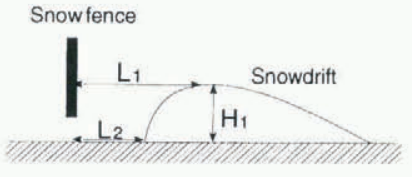

Fig. 5. Drift geometrical parameters.

Although Anno's model had a different geometry, Iversen proposed the same relation (see Equation (2)). In this case, $B$ is equal to $8.95 \times 10^{-5}$. Once more, we can explain the difference between the two orders of magnitude $\left(9.89 \times 10^{-4}\right.$ and $8.95 \times 10^{-5}$ ) by the concentration profiles in the wind tunnel. In the case of the experiments conducted by Anno, particles were ejected by compressed air and it may well be that they did not reach saturation.

\section{Influence of particle-concentration profiles on drift shape}

The experiments carried out in our wind-tunnel (Fig. 4) merit closer examination: the asymptotic behaviour of the curves seems to differ as a function of the fetch. This means that the particle concentration exerts an influence on the drift shape. In order to prove the above hypothesis, we have studied the geometrical parameters (Fig. 5) of drift precisely for the experiments represented in Figure 2. $L_{1}$ is the distance from the fence to the top of the drift, $L_{2}$ is the distance from the fence to the start of drift and $H_{1}$ is the maximum height of the drift.

For the same speed at the entry of the wind-tunnel testing section, the greater the fetch (and consequently the mass flux) is, the shorter the distances $L_{1}$ and $L_{2}$ are (Figs 6 and 7). We point out that the decrease in $L_{1}$ and $L_{2}$ is also a char-

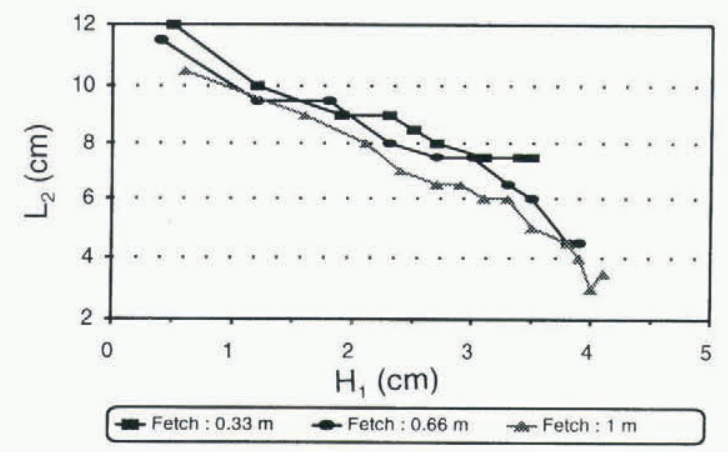

Fig. 6. $H_{1}$ vs $L_{2}$ for different fetches (same simulations as those represented in Figure 4)

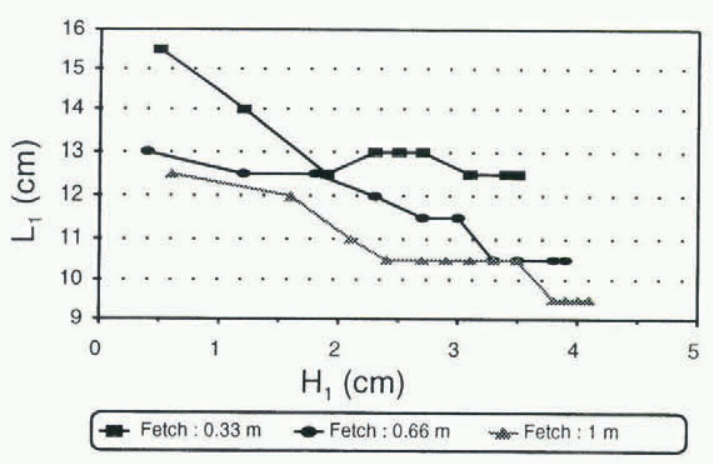

Fig. 7. $H_{1}$ vs $L_{1}$ for different fetches (same simulations as those represented in Figure 4).

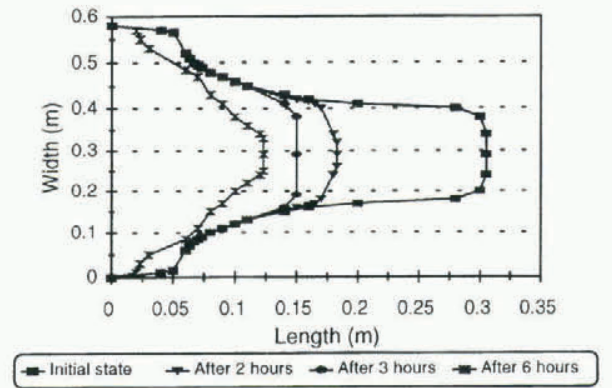

Fig. 8. Changes in the planform drift area as a function of time.

acteristic of a decrease in wind speed. Of course, the presence of the particles modifies the wind-speed profile since they extract momentum during aeolian transport. This wind-speed profile modification is sufficient to have an effect on drift shape. To include this effect, Anderson and Haff (1991) proposed adding to the turbulent Navier-Stokes equations an additional force term operating in the negative $x$ direction:

$$
\rho \frac{d \bar{\nu}_{\mathrm{i}}}{d t}=\left(\rho g_{\mathrm{i}}-\frac{\partial p}{\partial x_{\mathrm{i}}}+\frac{\partial \tau_{i j}^{1}}{\partial x_{j}}+\frac{\partial \tau_{i j}^{1}}{\partial x_{j}}-F_{\mathrm{i}}\right)
$$

where $F$ is a horizontal body force $\left(\mathrm{N} \mathrm{m}^{-3}\right)$ due to acceleration of the grains caused by the air during saltation.

The importance of the horizontal body force $F$ can be demonstrated by the following experiment: we have studied a sand drift behind a fence $4 \mathrm{~cm}$ high without porosity and without a bottom gap in a wind tunnel. The friction velocity at the entry to the testing section, windward of the erosion zone, was $40 \mathrm{~cm} \mathrm{~s}^{-1}$.

When snowdrift profile equilibrium was reached, we removed particles from the erosion zone and studied the evolution of the planform drift area as a function of time for the same friction velocity (Fig. 8).

There are two threshold velocities (Bagnold, 1941): the impact threshold and the fluid threshold. For sand, the impact threshold is about 0.8 of the fluid threshold. According to this idea, the drift must not be modified after removing the particles from the ablation zone, contrary to the observations (Fig. 6). However, the planform drift area decreases. It would appear that the fluid speed increases as a result of the lack of particles in the air stream. We can also explain this phenomenon by local instantaneous shear stresses on drift, generating a saltation-reptation process. But the reduction in the drift is too great to be explained only by this cause.

The presence of particles in the air stream therefore modifies the wind-speed profile due to the momentum extracted by the grains during aeolian transport. The fetch, and therefore the particle-concentration profiles, has a perceptible effect on drift shape.

\section{DISGUSSION AND GONGLUSIONS}

The particle-concentration profile influences drift-formation speed and drift shape. These results could explain the difference between the different published similitude requirements, particularly the storm-duration criterion. From an engineer's point of view, the observed difference between the shapes does not have great significance. On the other 
hand, it is of the utmost importance for accurately estimating snowdrift-formation speed. In order to improve this prediction by using physical or numerical simulation, it would be necessary to carry on with experiments similar to those undertaken by Takeuchi (1980) or to determine the splash function for different sorts of snow.

\section{REFERENCES}

Anderson, R. S. 1987. A theoretical model for aeolian impact ripples. Sedimentology, 34, 943-956.

Anderson, R. S. and P. K. Haff. 1991. Wind modification and bed response during saltation of sand in air. Acta Mech., Supplementum 1. Aeolian Grain Transport. 1: Mechanics, 21-52.

Anno, Y. 1984. Requirements for modeling of a snowdrift. Cold Reg. Sci. Technol., 8(3), 241-252.

Bagnold, R. A. 1941. The physics of blowing sand and desert dunes. London, Methuen.

Iversen, J. D. 1980. Drifting-snow similitude-transport-rate and roughness modeling. 7. Glaciol., 26 (94), 393-403.

Iversen, J. D. 1984. Comparison of snowdrift modeling criteria: commentary on "application of Anno's modeling conditions to outdoor modeling of snowdrifts". Cold Reg. Sci. Technol., 9(3), 259-265.
Kind, R. J. 1986. Snowdrifting: a review of modelling methods. Cold Reg. Sci. Technol., 12(3), 217-228.

Kobayashi, D. 1972. Studies of snow transport in low-level drifting snow. Contrib. Inst. Low Temp. Sci., Ser. A 24, 1-58.

Kosugi, K., K. Nishimura and N. Maeno. 1992. Snow ripples and their contribution to the mass transport in drifting snow. Boundary-Layer Meteorol., 59(1-2), 59-66.

Mellor, M. 1965. Blowing snow. CRREL Monogr. III-A3c.

Naaim, M. and H. Martinez. 1995. Experimental and theoretical determination of concentration profiles and influence of particle characteristics in blowing snow. Surv. Geophys., 16 (5-6), 695-710.

Naaim-Bouvet, F. 1995. Comparison of requirements for modeling snowdrift in the case of outdoor and wind tunnel experiments. Surv. Geophys., 16(5-6), 711-727.

Naaim-Bouvet, F. 1997. Contribution à la modélisation physique et numérique du transport de neige par le vent. (Thèse de doctorat, Université de Grenoble.)

Naaim-Bouvet, F., M. Naaim and H. Martinez. 1996. Profils de concentration de la neige soufflée: théorie, résolution et validation expérimentale in situ. Houille Blanche, 51 (5), 53-57.

Tabler, R. D. 1980. Self-similarity of wind profiles in blowing snow allows outdoor modeling. J. Glaciol., 26 (94), 421-434.

Takeuchi, M. 1980. Vertical profile and horizontal increase of drift-snow transport. F. Glaciol., 26(94), 481-492. 